\title{
Comparison of Rate and Progression of Myopia Among Carpet Weaver and Non-Weaver Members of the Weaver's Families in Birjand
}

\author{
Mohammad Hossien Davari, ${ }^{1}$ Hoda Gheitasi, ${ }^{2,}{ }^{*}$ and Esmat Davari ${ }^{3}$ \\ ${ }^{1}$ Atherosclerosis and Coronary Artery Research Center, Birjand University of Medical Sciences, Birjand, IR Iran \\ ${ }^{2}$ Department of Genetic, Translational Research, Laboratory 2 Hospital Duran I Reynolds, University of Barcelona, Barcelona, Spain \\ ${ }^{3}$ Department of Ophthalmology, Research Committee, Birjand University of Medical Sciences, Birjand, IR Iran \\ Corresponding author: Hoda Gheitasi, Physical Education Office, Ministry of Sciences, Tehran, IR Iran. E-mail: hoda24masoud@yahoo.com
}

Received 2015 April 03; Accepted 2015 June 24.

\begin{abstract}
Background: Refractive error is a common abnormality and the most common refractive error is myopia.

Objectives: The aim of this study was To Comparison of rate of myopia among carpet weaver and non-weaver members.

Methods: In this case-control study, all members of the weavers have been refracted objectively and subjectively by only one person.

Results: The relative frequency of moderate and severe myopia in carpet weaving significantly more than non-weavers $(\mathrm{P}<0.001)$.

The result of Variance Analysis (ANOVA) showed that by increasing the average duration of employment and working hours daily in

carpets, Myopia significantly more.

Conclusions: Sustained close distance working could have an effective role in progression and amount of myopia.
\end{abstract}

Keywords: Myopia, Carpet Weaver, Non- Weaver Members

\section{Background}

Of all the issues surrounding myopia in children, there is probably none so contentious yet crucial as understanding the relative contributions of environment, primarily near work and heredity. Several clinical studies have documented an association between myopia and higher levels of children's near work [1,2].

Epidemiological studies indicated that uncorrected refractive errors are accounted to be among the important risk factors for visual impairments in the world. Although genetic, racial, and environmental risk factors were identified as some factors influential on refractive errors [3].

Numerous studies showed that near work activity causes the myopic shift $[4,5]$.

The art of carpet weaving in Iran is becoming more industrialized and in many parts of Iran; it is done by individuals in their homes or workshops. Important body organs such as spinal cord are involved in this job. A carpet weaver works 8 hours daily.

\section{Objectives}

Considering the theories on close work and its effects on ocular biometry changes, the current study is carried out in an attempt to determine the relationship between rate and progression of myopia among carpet weaver and non-weaver members of the weaver's families.

\section{Methods}

In this case-control study 649 cases have been examined: 341 persons were carpets weavers and 308 nonweavers 83 (27\%) male, 225 (73\%) female (Table 1).

Inclusion criteria, all members of the weavers families in the region have invited through written letters to the eye clinic and all of them have been refracted by retinoscope and auto refractometer (Topcon Autorefractometer, model KM 8000, Japan), Slit lamp, Ophthalmoscope and Retinoscope (HEINE Optotechnic, Germany). Objectively and subjectively by only one person.

A questionnaire was filled in for every individual (demographic information, carpet weaving background, age of starting carpet weaving) and the results of examination were recorded. In the process of examination, there was made use of exclusion criteria were: corneal scar, keratoconous, keratoglobus, diabetes, cataract, glaucoma

Refractive errors found were classified with respect to their severity into the following four groups, normal, slight, moderate and severe. 0 - 0.50 normal, 0.75 - 2.75 low, 3.00 - 6.00 medium (moderate) and 6 up high (high) are considered.

Then they obtained data was statistically analyzed using SPSS. Myopia was defined as a spherical equivalent (SE) refraction of -0.50 diopter (D) or less and hyperopic as an SE refraction of +0.50 D or more. Emmetropia (normal) was defined as an SE between +0.50 and $-0.50 \mathrm{D}$. The study 
Table 1. Distribution of Refractive Errors in the Two Groups' Carpets and Non-Carpets ${ }^{\mathrm{a}}$

\begin{tabular}{|c|c|c|c|c|}
\hline Group & Myopia & Hyperopia & Normal & P Value \\
\hline Carpet weaver & $168(49.3)$ & $20(5.9)$ & $153(44.9)$ & $<0.001$ \\
\hline Non-carpets weaver & $104(33.8)$ & $48(15.6)$ & $156(50.6)$ & $<0.001$ \\
\hline Total & $272(41.9)$ & $68(10.5)$ & $309(47.6)$ & $<0.001$ \\
\hline
\end{tabular}

${ }^{\mathrm{a}}$ Values are expressed as No. (\%).

protocol was approved by the ethical committee of Birjand University of Medical sciences. Data was analyzed by SPSS 16 software and one-way ANOVA and rang-Tukey.

\section{Results}

Six hundred forty nine cases have been examined: 341 persons were carpets weavers and 308 non-weavers 83(27\%) male, 225 (73\%) female (Table 1).

Two hundred forty nine patients in carpets weavers (73 $\%)$ and 225 patients in non-carpets (73.1\%) were female ( $\mathrm{P}=$ 0.99).

One hundred sixty eight persons carpets (49.3\%) and 104 persons non carpets (33.8\%) were with myopia and 20 patients carpets ( $5.9 \%$ ) and 48 patients non carpets (15.6\%) were with hyperopia $(\mathrm{P}<0.001)$ (Table 1$)$. The relative frequency of moderate and severe myopia in carpet weaving significantly more than non-weavers $(\mathrm{P}<0.001)$ (Table 2$)$.

The result of variance analysis (ANOVA) showed that by increasing the average duration of employment and working hours daily in carpets, Myopia significantly more, but the average age of onset carpet weaving significantly less (Table 3).

The average duration of employment, hours of work per day and the average age of onset of weaving carpets in patients with hyperopia, respectively are; $25.4 \pm 89.2,26.1$ $\pm 00.4,52.3 \pm 21.12$. On the basis of data, the result was that the rate and progression of myopia was twice more among weaver member family in respect to non-weaver family members. According to these results we can say that carpentry (working near the eye) can be a factor involved in creating or exacerbating myopia

\section{Discussion}

Our finding indicates that myopia among members of a family involved in carpet weaving is more common compared to those members not involved in carpet weaving. Genetic factors are generally the same in both groups. In this study, both heredity and near work were significantly associated with myopia, with heredity being the more important factor. This fact light over such an environmental factor as close work.

The association of close work with the refractive status especially myopia was a hypothetical consideration for a time in the past. In 1995 Chen studied 110 individuals working with diamond (Small, expensive pieces of stones) and reached the conclusion that myopia was more common among those who involved in close work [6].

Mutti et al. [7] in study, Parental Myopia, Near Work, school achievement, and children's refractive error: They also found no evidence to support the theory that heredity is important only because parents with myopia have children who do more near work. Children of parents without myopia did as much near work as children of parents with myopia. This is consistent with previous studies that report on both near work and parental history of refractive error. Bear et al. [8] found little change in correlations between the refractive errors of family members after adjustment for the current level of near work, suggesting a strong genetic component independent of near work. Although Wong et al. [9] reported significant odds ratios for both hours per day of reading and familial tendency toward myopia; they did not assess the effect of each variable on the other by comparing univariate and multivariate odds ratios. In a sample of Singaporean conscripts with a highly myopic average refractive error of -6.1 D, Saw et al. [10] found that parental myopia was significantly related to myopia, but neither past nor current near work was a confounding variable, because near work was not associated with myopia. Parental myopia became no significant when adjusted not for near work, but for educational level and placement in a pour study highlights the role of environmental factors. In carpet weaving the eyes have to focus on close objects like the carpet frame. On the other hand, the worker cannot see distant objects because the carpet frame and the surroundings don't provide such an opportunity during working. Most carpet weavers under study work early in the morning until late in the afternoon and in between they have a short break for their lunch.

Therefore carpet weaving with the about mentioned circumstances is an example of close continuous oph- 
Table 2. Distribution of Myopia Severity in Both Groups Carpets and Non-Carpets ${ }^{\mathrm{a}}$

\begin{tabular}{|c|c|c|c|c|}
\hline Group & Low & Moderate & High & P Value \\
\hline Carpet weaver & $68(40.5)$ & $78(46.4)$ & $22(13.1)$ & $<0.001$ \\
\hline Non-carpets weaver & $59(56.7)$ & $32(30.8)$ & $13(12.5)$ & $<0.001$ \\
\hline Total & $81(29.8)$ & $110(40.4)$ & $81(29.8)$ & $<0.001$ \\
\hline
\end{tabular}

${ }^{\mathrm{a}}$ Values are expressed as No. (\%).

Table 3. Compare the Average Duration of Employment, Hours of Work Per Day and the Average Age of Onset in Patients Weaving Carpets According to Severity of Myopia ${ }^{\text {a }}$

\begin{tabular}{lcccc}
\hline Myopia & No. & $\begin{array}{c}\text { Duration } \\
\text { occupation }\end{array}$ & Hours & Ptart age \\
\hline Normal & 153 & $16.48 \pm 4.25$ & $5.2 \pm 2.72$ & $12.47 \pm 3.5$ \\
\hline Low & 68 & $19.55 \pm 3.68^{\mathrm{b}}$ & $7.99 \pm 3.21^{\mathrm{b}}$ & $11.06 \pm 3.42^{\mathrm{b}}$ \\
\hline Moderate & 78 & $18.22 \pm 3.76^{\mathrm{b}, \mathrm{c}}$ & $8.84 \pm 3.11^{\mathrm{b}, \mathrm{c}}$ & $9.84 \pm 2.85^{\mathrm{b}, \mathrm{c}}$ \\
\hline High & 22 & $20.77 \pm 4.22^{\mathrm{b}, \mathrm{c}, \mathrm{d}}$ & $9.23 \pm 4.23^{\mathrm{b}, \mathrm{c}, \mathrm{d}}$ & $9.30 \pm 2.67^{\mathrm{b}, \mathrm{c}, \mathrm{d}}$ \\
\hline
\end{tabular}

${ }^{\mathrm{a}}$ Values are expressed as mean $\pm \mathrm{SD}$.

${ }^{\mathrm{b}}$ Normal.

${ }^{\mathrm{c}}$ Low.

${ }^{\mathrm{d}}$ Moderate.

${ }^{\mathrm{e}}$ High.

thalmic work that first the theory of over accommodation.

It increases the severity of acquired myopia through hypertrophy of cilia muscles. In general close work and continuous accommodation as in carpet weaving may increase the severity of myopia [11].

Generally, comparison of this finding with the results of the previous studies which have been accomplished in Iran shows that the occurrence of myopia is high in the carpet weaving population. In a study performed based on cycloplegic and non cycloplegic refractions in Tehran, Iran, the incidence of myopia was $17.20 \%$ and $21.80 \%$ respectively [12]. Also, in a report concerning the elderly population in Mashhad, the incidence of myopia has been shown to be $27.20 \%$. Investigation of these studies shows that the occurrence of myopia is high in carpet weaver's population. Comparing this result with the incidence of myopia in the healthy population of other studies, we see that the prevalence of myopia in the carpet weavers is more than that in many of other studies [11].

We find that myopia among members of a family involved in carpet weaving is more common (twice) compared to those members not involved in carpet weaving.

The previous studies reported that near work is the reason for myopia progressions. Refractive errors have previously been investigated in some occupations such as computer, operators, typists, and microscopes that have near work activities. In addition to near work, other factors such as environmental and genetic factors play a role in progres- sion of myopia [13].

\section{Acknowledgments}

This article is the outcome of the research project (No. 304) that Supervised by Davari, and consulted by Gheitasi. We are obliged to thank our colleagues in the unit for eye clinic of Birjand Valli-e-asr hospital, particularly Mrs. Sanaei, who assisted us in this research.

\section{Footnotes}

Authors' Contribution: All authors had equal role in design, work, statistical analysis and manuscript writing.

Funding/Support: Birjand University of Medical Sciences.

\section{References}

1. Zylbermann R, Landau D, Berson D. The influence of study habits on myopia in Jewish teenagers. J Pediatr Ophthalmol Strabismus. 1993;30(5):319-22. [PubMed: 8254449].

2. Zadnik K, Satariano WA, Mutti DO, Sholtz RI, Adams AJ. The effect of parental history of myopia on children's eye size. JAMA. 1994;271(17):1323-7. [PubMed: 8158816].

3. Warrier S, Wu HM, Newland HS, Muecke J, Selva D, Aung T, et al. Ocular biometry and determinants of refractive error in rural Myanmar: the Meiktila Eye Study. Br J Ophthalmol. 2008;92(12):1591-4. doi: 10.1136/bjo.2008.144477. [PubMed: 18927224]. 
4. Wong TY, Foster PJ, Ng TP, Tielsch JM, Johnson GJ, Seah SK. Variations in ocular biometry in an adult Chinese population in Singapore: the Tanjong Pagar Survey. Invest Ophthalmol Vis Sci. 2001;42(1):73-80. [PubMed: 11133850].

5. McBrien NA, Adams DW. A longitudinal investigation of adult-onset and adult-progression of myopia in an occupational group. Refractive and biometric findings. Invest Ophthalmol Vis Sci. 1997;38(2):32133. [PubMed: 9040464].

6. Chen CJ, Cohen BH, Diamond EL. Genetic and environmental effects on the development of myopia in Chinese twin children. Ophthalmic Paediatr Genet. 1985;6(1-2):353-9. [PubMed: 4069597].

7. Mutti DO, Mitchell GL, Moeschberger ML, Jones LA, Zadnik K. Parental myopia, near work, school achievement, and children's refractive error. Invest Ophthalmol Vis Sci. 2002;43(12):3633-40. [PubMed: 12454029].

8. Bear JC, Richler A, Burke G. Nearwork and familial resemblances in ocular refraction: a population study in Newfoundland. Clin Genet. 1981;19(6):462-72. [PubMed: 7296938].

9. Wong L, Coggon D, Cruddas $\mathrm{M}$, Hwang $\mathrm{CH}$. Education, reading, and familial tendency as risk factors for myopia in Hong Kong fishermen JEpidemiol Community Health. 1993;47(1):50-3. [PubMed: 8436895].

10. Saw SM, Wu HM, Seet B, Wong TY, Yap E, Chia KS, et al. Academic achievement, close up work parameters, and myopia in Singapore military conscripts. Br J Ophthalmol. 2001;85(7):855-60. [PubMed: 11423462].

11. Saw SM, Chua WH, Hong CY, Wu HM, Chan WY, Chia KS, et al. Nearwork in early-onset myopia. Invest Ophthalmol Vis Sci. 2002;43(2):3329. [PubMed: 11818374].

12. Yekta AA, Fotouhi A, Khabazkhoob M, Hashemi H, Ostadimoghaddam $\mathrm{H}$, Heravian J, et al. The prevalence of refractive errors and its determinants in the elderly population of Mashhad, Iran. Ophthalmic Epidemiol. 2009;16(3):198-203. doi: 10.1080/09286580902863049. [PubMed: 19437316].

13. Jimenez JR, Bermudez J, Rubino M, Gomez L, Anera RG. Prevalence of myopia in an adult population of two different ethnic groups in the Ecuadorian Amazon. Jpn J Ophthalmol. 2004;48(2):163-5. doi: 10.1007/s10384-003-0041-z. [PubMed: 15064973]. 